\title{
The Impacts of Climate Variability on Cholera Cases in Malaysia
}

Hassan $N A^{\mathrm{a}, \mathrm{b}, \mathrm{c}}$, Hashim $\mathrm{JH}^{\mathrm{b}, \mathrm{c}, \mathrm{d}}$, Wan Puteh $\mathrm{SE}^{\mathrm{b}}$, Wan Mahiyuddin $\mathrm{WR}^{\mathrm{e}}$, Faisal $M \mathrm{~S}^{\mathrm{f}}$

aDepartment of Community Medicine, Kulliyyah of Medicine, International Islamic University Malaysia, 25200 Kuantan, Pahang, Malaysia

bepartment of Community Health, Faculty of Medicine, UKM Medical Centre, Bandar Tun Razak, 56000 Kuala Lumpur, Malaysia

'United Nations University-International Institute for Global Health, UKM Medical Centre, Bandar Tun Razak, 56000 Kuala Lumpur, Malaysia

dDepartment of Health Sciences, UNISEL, 40000 Shah Alam, Selangor, Malaysia

eInstitute for Medical Research, 50588 Kuala Lumpur, Malaysia

${ }^{f}$ National Hydraulic Research Institute of Malaysia, Ministry of Environment , 43300 Seri Kembangan, Selangor, Malaysia

\section{ABSTRACT}

Introduction: Altered weather patterns and changes in precipitation, temperature and humidity resulting from climate change could affect the distribution and incidence of cholera. This study is to quantify climateinduced increase in morbidity rates of cholera. Material and Methods: Monthly cholera cases and monthly temperature, precipitation, and relative humidity data from 2004 to 2014 were obtained from the Malaysian Ministry of Health and Malaysian Meteorological Department, respectively. Poisson generalized linear models were developed to quantify the relationship between meteorological parameters and the number of reported cholera cases. Results: The findings revealed that the total number of cholera cases in Malaysia during the 11 year study period was 3841 cases with 32 deaths. Out of these, $45.1 \%$ of the cases were among children below 12 years old and $75 \%$ of the cases were from Sabah. Temperature and precipitation gave significant impact on the cholera cases in Sabah, $(p<0.001)$ while precipitation were significant in Terengganu $(p<0.001)$, and Sarawak $(p=0.013)$. Monthly lag temperature data at Lag 0,1 , and 2 months were associated with the cholera cases in Sabah $(p<0.001)$. The change in odds of having cholera cases were by the factor of 3.5 for every $1^{\circ} \mathrm{C}$ increase in temperature. However, the contribution of rainfall was very mild, whereby an increase of $1 \mathrm{~mm}$ in precipitation will increase the excess risk of cholera by up to $0.8 \%$. Conclusion: This study concludes that climate does influence the number of cholera cases in Malaysia.

KEYWORDS: Cholera, Malaysia, Sabah, temperature, precipitation

\section{INTRODUCTION}

Cholera is one of the climate sensitive diseases that remains a global threat to human health because of its high Case Fatality Rate (CFR) and endemic Corresponding Author:

Asst. Prof. Dr. Noor Artika Hassan

Department of Community Medicine, Kuliyyah of Medicine, International Islamic University Malaysia, 25200 Kuantan, Pahang, Malaysia

Tel No : +609 - 5704601 Ext: 4602

Email : noor_artika@iium.edu.my nature. The CFR can be as high as $30-50 \%$ for untreated cholera, but prompt administration of oral rehydration therapy can reduce it to $1 \% .^{1}$ It is estimated that there were 1.3 to 4.0 million cases which caused 21,000 to 143,000 deaths worldwide annually. ${ }^{2}$ The number of cholera cases reported to the World Health Organization (WHO) is consistently high. During 2013, a total of 129,064 cases were notified from 47 countries, including 2,102 deaths. 
Out of these, 11,576 cases and 100 deaths were from the Asian region which contributed to the CFR of $0.86 \%{ }^{3}$

Vibrio cholerae, the causative agent of cholera, can survive up to two weeks in fresh water and eight weeks in salt water. It can spread to humans through infected drinking water, shellfish, food contaminated by flies or the hands of carriers, and directly from person to person by the faecal-oral route. ${ }^{2}$ Its diagnosis is based on the identification of Vibrio cholerae 01 or 0139 from stool samples of any patient with diarrhoea. Cholera has a short incubation period between 2 hours to 5 days which explains the potentially explosive nature of outbreaks. Cholera is commonly related to water, sanitation and hygiene issues. However, in the past few years, researchers have begun to investigate the associations between weather and the incidence of cholera. Changes in rainfall, ambient temperature, and relative humidity patterns have been suggested to play a role. ${ }^{4,5}$

In Malaysia, cholera is considered as a non-endemic disease with 2,293 expected cases and 24 deaths annually. ${ }^{6}$ It is listed as one of the notifiable diseases that should be reported under the jurisdiction of the Communicable Disease Control Division, Ministry of Health. This article is to quantify climate-induced increases in the morbidity rates of cholera in Malaysia. The study area consisted of all 13 states in Malaysia including Sabah and Sarawak which encompasses a population of 32 million. Each state in Malaysia has varying population sizes, ranging from 0.2 million to 3.5 million population.

\section{METHODOLOGY}

\section{Data on cholera cases and climate}

Monthly cholera cases and monthly meteorological data (temperature, precipitation, and relative humidity) from 2004 to 2014 were obtained from the Malaysian Ministry of Health and Malaysian
Meteorological Department, respectively. For demographic data, information such as name list of patient, address, district, mukim, age, gender, race, date of onset, date of record, and date of analysis were compiled. All confirmed cholera cases diagnosed on or after $1^{\text {st }}$ January 2004 until $31^{\text {st }}$ December 2014 were included in the study. All incomplete information without the dates of onset, sampling, and diagnosis were rejected.

For the meteorological data, there were 39 stations for temperature and relative humidity, and 115 stations for precipitation for the whole of Malaysia. Missing data in this study were classified as Missing Completely at Random (MCAR). The missing data only occurred for the meteorological data, specifically on precipitation. This was due to equipment breakdown, or the equipment was transferred to other more important stations especially during flood events. Missing data were estimated by using multiple regression analysis. Missing data (vo) were estimated as ao, ai are regression coefficients. $\mathrm{Vi}$ is the value of the weather stations. ${ }^{7}$

$$
v o=a o+\sum_{i=1}^{n}(a i V i)
$$

Preliminary analysis found a high colinearity between relative humidity and precipitation. Due to Malaysia receiving high precipitation in certain states and being prone to floods, precipitation was chosen instead of relative humidity. In addition, there is very limited information in the literature on the relationship between relative humidity with cholera compared to precipitation.

\section{Analysis}

Poisson generalized linear models were developed to quantify the relationship between monthly lag 0 to lag 2months meteorological data and the number of reported cholera cases. Poisson regressions were used when the mean and the variance are similar while in the case of overdispersion, Poisson 
controlled for overdispersion were used. To control were among immigrants in Sabah. Sabah has 25 for the overdispersion, the scale weight was districts, and $33.3 \%$ of the cases were from the introduced by dividing the deviance or Pearson chi- District of Semporna, 8.6\% from Kota Kinabalu, 6.2\% square to 1. Time stratified model and fourier terms from Tawau, 5.4\% from Kota Belud, 5.1\% from Kudat, were introduced to control long-term trends and $4.8 \%$ from Putat, $4.4 \%$ from Tuaran, $4.4 \%$ from Lahad seasonality, respectively.

Datu, $4.3 \%$ from Kunak, and the rest were less than 4.0\%. Interestingly, all these districts were along the

Regression analyses for this study were conducted using IBM SPSS Statistics version 22. The analysis is considered as pooled health impacts, instead of as individual impacts. The potential effect of trend, and seasonality were also assessed. The years were set up as an offset.

This modeling framework was accommodated as expressed in Equations (1) to (3):

Yi $\sim \operatorname{Pois}\left(u_{i} \lambda_{i}\right)$

$\log \left(u_{i} \lambda_{i}\right)=\log \left(u_{i}\right)+\log (\lambda i)(2)$

$\log (\lambda i)=X i B$

where, $u_{i}$ is the exposed population at that time; $\lambda_{i}$ is the expected number of cases as a fraction of the exposed population; $X i$ is the regression matrix ; and $B$ is the vector of model coefficients. ${ }^{8}$

Sensitivity testing was done to assess the sensitivity of the significant parameters by replacing one of variables being studied. In this study, lag data were used due to the unavailability of minimum and maximum temperature data and small variations in the temperature range in Malaysia.

\section{RESULTS}

\section{Demography of cholera cases}

The findings revealed that the total number of cholera cases in Malaysia during the 11year study period was 3841 cases with 32 deaths (Table 1 ).

Of these, $75.4 \%$ of the cases were from Sabah, $10.4 \%$ were from Terengganu, followed by Sarawak (6.5\%), Kelantan $(3.0 \%)$ and Selangor (2.9\%). Most of the cases were among Malaysians while $30 \%$ of the cases coastal areas in Sabah (including the percentages of below $4.0 \%$ such as Sandakan, Pitas, and Kota Marudu).

The same phenomenon occurred in Terengganu and Sarawak, whereby the districts affected were those nearby coastal areas. In Terengganu, $74.8 \%$ of the cases were from Kuala Terengganu, 14.5\% from Marang, followed by other districts, whereas in Sarawak, $43.6 \%$ were from Bintulu, $53.6 \%$ from Limbang, and the rest from other districts.

Table I: Demographic information of the cholera cases in Malaysia

\begin{tabular}{ll}
\hline Demographic Data & Cholera, N (\%) \\
\hline Gender & $1923(50.10 \%)$ \\
Male & $1918(49.10 \%)$ \\
Female & \\
Mean \pm SD & $21 \pm 19$ years old \\
$<12$ years old & $1704(45.10 \%)$ \\
$13-24$ years old & $745(19.70 \%)$ \\
$25-59$ years old & $1102(29.20 \%)$ \\
$>60$ years old & $226(6.00 \%)$ \\
Nationality & \\
Malaysian & $2700(70.30 \%)$ \\
Non-Malaysian & $1141(29.70 \%)$ \\
Death & $32(0.84 \%)$ \\
\hline
\end{tabular}

Demographic distributions of the cases are presented in Table 1. This study found that young children bore the greatest burden of cholera which constituted $45.1 \%$ of the cases.

The finding was consistent with other research that showed cholera as a significant problem in young children. ${ }^{8}$ Cholera is transmitted via the faecal-oral 
route. Children are usually dependant on adults to take care of their hygiene.

\section{Climate in Malaysia}

Malaysia is a tropical country located near the equator with a hot and humid climate throughout the year. Data from the Meteorological Department showed that the mean temperature in each state did not indicate huge differences. It ranged from $24.7^{\circ} \mathrm{C}$ to $30.0^{\circ} \mathrm{C}$. Generally, April, May and June were indicated as the hottest months of the year as $50.0 \%$ of the recorded temperatures were $29.0^{\circ} \mathrm{C}$ and above. December and January presented the lowest temperatures in Malaysia with $60.0 \%$ and $40.0 \%$ of the temperatures below $25.0^{\circ} \mathrm{C}$ in January and December, respectively.

Higher temperatures were recorded during the southwest monsoon and lower temperatures were recorded during the northeast monsoon. During the southwest monsoon, Malaysia receives less precipitation which causes the rise in surface temperature in May and June.

Besides the monsoon, the occurrence of heat waves aggravated the temperature increase in certain states notably from March to June in 2014. During the northeast monsoon, the abundant rainfall decreases the surface temperature which resulted in cooler temperatures in all states.

Several states in the east coast of West Malaysia such as Pahang, Kelantan and Terengganu received higher precipitation amount during the northeast monsoon season which resulted in annual flooding events. In these 11 years period, the highest precipitations were recorded in 2014 at Kemaman, followed by Jerangau and Kuala Krai with $1730 \mathrm{~mm} / \mathrm{month}$, $1728 \mathrm{~mm} / \mathrm{month}$ and $1387 \mathrm{~mm} /$ month, respectively.

The precipitation caused a major flood disaster called "Bah Kuning" (yellow-coloured flood) and was believed to be the worst flood event in the last 50 years.

\section{Association between meteorological data and cholera incidence}

Tables 2 and 3 show the relationship between climate variability and cholera cases at Lag 0 to Lag 2 months. The analyses were run for six states where there were cholera cases. Sabah is the only state that showed a positive association at Lag 0 with temperature, precipitation, and trend $(p<0.001)$.

The change in odds of having cholera cases were by the factor of 3.5 for every $1^{\circ} \mathrm{C}$ increase in temperature. For precipitation, the results indicated that for every $1 \mathrm{~mm}$ increase in monthly precipitation, there was a $0.6 \%$ to $0.8 \%$ increase in cholera cases in Sabah, and Terengganu. In Sarawak, precipitation is a protective factor $(p=0.013)$. Other states such as Kedah, Kelantan and Selangor showed that the cholera cases were associated only with seasonality and trends.

Due to the low number of cases in Terengganu and Sarawak, only Sabah was tested for Lag 1 and Lag 2 months. Results indicated that there were association of temperature with the cholera cases at Lag 1 and Lag 2 months while for precipitation, it only associated with the cholera cases at Lag 1 month.

The results were coherent with the distribution of cases as it shows that the highest cholera cases in Sabah were in the southwest monsoon from April to June, which is a hotter period, while in Terengganu, it occurred during the October to December which were in the inter-monsoon and the northeast monsoon seasons. In contrast with Terengganu, cholera cases in Sarawak occurred during the southwest monsoon from July to August with the average precipitation of $200 \mathrm{~mm}$ to $400 \mathrm{~mm}$ per month. 
Table II : Poisson generalized linear model coefficients for cholera incidence ( Lag 0 ) in selected states of Malaysia

\begin{tabular}{|c|c|c|c|c|}
\hline Coefficients & Model Value & Confidence Interval & $\operatorname{Exp}(B)$ & $\mathrm{p}$-value \\
\hline \multicolumn{5}{|l|}{ Sabah** } \\
\hline Temperature & 1.259 & 2.244 to 5.529 & 3.523 & $<0.001^{*}$ \\
\hline Precipitation & 0.006 & 1.003 to 1.008 & 1.006 & $<0.001^{*}$ \\
\hline Seasonality & 0.223 & 0.914 to 0.923 & 0.918 & 0.144 \\
\hline \multicolumn{4}{|l|}{ Terengganu } & $<0.001^{*}$ \\
\hline Temperature & 0.870 & 0.929 to 6.132 & 2.387 & 0.071 \\
\hline Precipitation & 0.008 & 1.005 to 1.010 & 1.008 & $<0.001^{*}$ \\
\hline Seasonality & -0.524 & 0.302 to 1.159 & 0.592 & 0.126 \\
\hline Long term trend & -0.088 & 0.903 to 0.929 & 0.916 & $<0.001^{*}$ \\
\hline $\begin{array}{l}\text { Sarawak } \\
\text { Temperature }\end{array}$ & -0.591 & 0.169 to 1.474 & 0.499 & 0.209 \\
\hline Precipitation & -0.006 & 0.989 to 0.999 & 0.994 & $0.013^{*}$ \\
\hline Seasonality & 0.533 & 1.311 to 2.217 & 1.705 & $<0.001^{*}$ \\
\hline Long term trend & -0.061 & 0.930 to 0.951 & 0.940 & $<0.001^{*}$ \\
\hline \multicolumn{5}{|l|}{ Kedah } \\
\hline Temperature & -0.005 & 0.037 to 2.935 & 0.995 & 0.992 \\
\hline Precipitation & 0.00 & 0.998 to 1.009 & 1.004 & 0.199 \\
\hline Seasonality & 0.770 & 0.696 to 6.700 & 2.159 & 0.183 \\
\hline Long term trend & -13.518 & $\begin{array}{l}1.907 \mathrm{E}-7 \text { to } 9.504 \mathrm{E}- \\
6\end{array}$ & $1.346 \mathrm{E}-6$ & $<0.001^{*}$ \\
\hline \multicolumn{5}{|l|}{ Kelantan** } \\
\hline Temperature & 0.336 & 0.691 to 2.830 & 1.399 & 0.351 \\
\hline Precipitation & 0.001 & 0.998 to 1.003 & 1.001 & 0.641 \\
\hline Seasonality & -1.027 & 0.188 to 0.682 & 0.358 & $0.002^{*}$ \\
\hline Long term trend & 0.253 & 0.479 to 3.460 & 1.287 & 0.616 \\
\hline \multicolumn{5}{|l|}{ Selangor** } \\
\hline Temperature & -0.175 & 0.608 to 1.159 & 0.839 & 0.287 \\
\hline Precipitation & 0.001 & 0.99 to 1.004 & 1.001 & 0.327 \\
\hline Seasonality & -0.205 & 0.621 to 1.068 & 0.815 & 0.137 \\
\hline Long term trend & -0.008 & 0.987 to 0.997 & 0.992 & $0.004^{*}$ \\
\hline
\end{tabular}

${ }^{* *}$ Overdispersed Poisson

*Significance at $p<0.05$

\section{DISCUSSION AND CONCLUSION}

The study revealed that most of the cholera cases in Malaysia occurred in the coastal states and the highest number of cases were in Sabah. The occurrence of this phenomenon might be due to the nature of Vibrio cholerae, which is usually present in the estuarine and coastal ecosystems. ${ }^{10}$ The bacterium is strongly associated with planktons, forming commensal or symbiotic relationships, mainly 
Table III : Estimated model coefficients for cholera (Lag 1 and Lag 2 months)

\begin{tabular}{|c|c|c|c|c|}
\hline Coefficients & Model Value & Confidence Interval & $\operatorname{Exp}(B)$ & p-value \\
\hline \multicolumn{5}{|c|}{ Lag 1 month temperature } \\
\hline Temperature & 0.807 & 1.501 to 3.347 & 2.241 & $<0.001^{*}$ \\
\hline Precipitation & 0.002 & 1.001 to 1.005 & 1.002 & $0.022^{*}$ \\
\hline Seasonality & 0.760 & 1.515 to 3.019 & 2.139 & $<0.001^{*}$ \\
\hline Long term trend & -0.001 & 0.993 to 1.004 & 0.999 & 0.589 \\
\hline \multicolumn{5}{|c|}{ Lag 2 month temperature } \\
\hline Temperature & 0.852 & 1.449 to 3.794 & 2.345 & $0.001^{*}$ \\
\hline Precipitation & 0.002 & 1.000 to 1.004 & 1.002 & 0.107 \\
\hline Seasonality & 0.946 & 1.723 to 3.850 & 2.576 & $<0.001$ \\
\hline Long term trend & -0.002 & 0.992 to 1.003 & 0.998 & 0.456 \\
\hline \multicolumn{5}{|c|}{ Lag 1 month precipitation } \\
\hline Temperature & 0.608 & 1.099 to 3.068 & 1.836 & $0.020^{*}$ \\
\hline Precipitation & 0.001 & 0.998 to 1.003 & 1.000 & 0.733 \\
\hline Seasonality & 0.498 & 1.194 to 2.266 & 1.645 & $0.002^{*}$ \\
\hline Long term trend & -0.002 & 0.993 to 1.004 & 0.998 & 0.513 \\
\hline \multicolumn{5}{|c|}{ Lag 2 month precipitation } \\
\hline Temperature & 0.606 & 1.143 to 2.942 & 1.833 & $0.012^{*}$ \\
\hline Precipitation & 0.001 & 0.999 to 1.003 & 1.001 & 0.486 \\
\hline Seasonality & 0.479 & 1.154 to 2.259 & 1.615 & $0.050^{*}$ \\
\hline Long term trend & -0.002 & 0.992 to 1.003 & 0.998 & 0.394 \\
\hline
\end{tabular}

with copepods. A study conducted in Bangladesh to $28.9^{\circ} \mathrm{C}$. The highest number of cases were in April showed that the cholera cases were reduced by $48 \%$ and June during which it is warmer with less rain due when they filtered the copepods and particulates of to the southwest monsoon season. Other than more than $20 \mu \mathrm{m}$ from the water before use. ${ }^{11}$ In copepods, many studies have proven that warmer Sabah, limited information was found on the copepods temperatures especially during summer months, will in the water. However, there was a study done on bloom many other planktonic species such as muddy and sandy sediments in Kok Lawi Beach, Sabah. Cyanobacteria (Blue-green algae), diatoms, and The results found out that there were 2632 copepods Pfiesteriapiscicida. ${ }^{13}$ Algae will be consumed by fish, in the samples taken. It was found in 5 to $15 \mathrm{~cm}$ depth mollusc and crustacean, and a heavy intrusion of of the sand. ${ }^{11}$ It has been determined that a single carriers infected with Vibrio cholerae was generated copepod, depending on size and species, can carry up and distributed into multiple coastal communities. to 10,000 cells of Vibrio cholera. ${ }^{10}$

This might explain why in Malaysia, most of the cholera cases happened in the coastal areas. They

Salinity of $15 \%$ and temperature ranging from $25^{\circ} \mathrm{C}$ to consume more seafoods such as mussels, oysters, $30^{\circ} \mathrm{C}$ have been shown to be important in influencing clams, mud creeper and other species that might be the attachment of Vibrio cholerae to copepods. ${ }^{11}$ In contaminated with Vibrio cholerae.

Sabah, temperature is one of the significant factors contributing to cholera cases. Findings from this study In Sabah, for every $1{ }^{\circ} \mathrm{C}$ unit increase in monthly is consistent with other findings as $90 \%$ of the cases in temperature, the change in odds of having cholera is Malaysia occurred at temperatures ranging from $26^{\circ} \mathrm{C}$ by the factor of 3.5. Precipitation gave a lesser 
influence on cholera cases in Malaysia, whereby an increase of $1 \mathrm{~mm}$ in monthly precipitation, it will increase the cholera cases by up to $0.8 \%$. The lag data showed the current monthly temperature could be the optimum temperature for the cholera outbreak up to the next 2 months while for precipitation, it could be the optimum precipitation up to the next month. Cholera cases in Terengganu obviously occurred during the rainy season. The northeast monsoon will bring heavy rain to the east coast states causing annual flood events. Floods can be the vehicle for the pathogenic bacteria from human and animal excreta in the soil to the river or any drinking water source, thus increasing the risk of getting cholera. In Sarawak, the cholera cases occurred during the dry season. Although dry season usually associated with high temperature, however, temperature was not significantly associated with cholera cases in Sarawak.

There are limited number of studies to compare the association between climate and cholera cases. Most of the studies include cholera diseases in the total diarrhoeal cases, and not studied alone. ${ }^{8,14,15}$ Luque Fernandez et al. ${ }^{17}$ in their study investigated the association of temperature and precipitation with cholera cases. However, they used the weekly data instead of monthly data and lagged the data up to 6 weeks. They demonstrated that for every $1.0{ }^{\circ} \mathrm{C}$ increase in temperature 6 weeks before the onset of the outbreak, it explained $5.2 \%$ of the increase in cholera cases, while for every $50 \mathrm{~mm}$ increase in rainfall 3 weeks before, it explained $2.5 \%$ of the increase in cholera cases. The excess risks in their study were different compared to this study which might be due to the differences in terms of the number of cases in Zambia and Malaysia. The number of cases in Zambia were very high and can reach up to 911 cases per week, while in Malaysia the maximum monthly cases were below 200. Therefore, $5.2 \%$ in Zambia indicated higher cases compared to Malaysia. In addition, the difference might be due to the difference in temperature and precipitation distributions in both countries as they used the maximum and minimum weekly data while this study used the mean monthly data. Weekly data will be more accurate compared to monthly data due to the incubation period of cholera is less than 7 days, however, due to financial constraint, the author had to use the mean monthly data.

There was another study conducted by Reyburn et al. $^{21}$ to find the association between climate variability and cholera cases by using the SARIMA model. The outcome of their study was that cholera cases was not associated with temperature and rainfall at 0 month lag but the association started to be seen at 1 month lag. Similar to Luque Fernandez et al., ${ }^{17}$ Reyburn et al. ${ }^{21}$ used the minimum and maximum temperature instead of the mean temperature.

The cholera situation in Sabah is complex and multifactorial. Besides the climatic factors, there are many water houses and longhouses in Sabah, and immigrants' issue. Some of cases are identified in illegal settlements with poor sanitation. ${ }^{22}$ A study by $\operatorname{Zin}^{6}$ conducted in Beluran, a place where there were outbreaks of cholera due to contaminated ice cubes, $^{18}$ showed that out of 114 households interviewed from 3 villages, 37-63\% had no latrine at home, only $57-74 \%$ practiced hand washing after using the toilet, $52-60 \%$ still depended on rain water, and $40-48 \%$ used a combination of rain and surface water for daily activities.

Compared to Sabah, Terengganu, Sarawak, Kelantan and Selangor had lower cholera cases. Selangor is one of the most populous states in Malaysia. Eating outside in the restaurants during work days is a normal practice. People can easily get infection through foods either during preparation, storage or serving. Kelantan and Terengganu are flood prone states. This study shows that $97.8 \%$ of the cholera cases in Terengganu occurred during November and December, while $22.6 \%$ of the cases were recorded in 
Kelantan during the same period. The northeast monsoon will bring heavy precipitation to the east coast states. People might get infected from the contaminated food and water supply during floods.

Global environmental and climatic changes are 5 expected to worsen the episodes of cholera cases. More outbreaks will occur as a result of an increase in temperature. The marine microbiota may provide more reservoirs for Vibrio Cholerae. Temperature rise causes warmer atmosphere, which leads to an increase in water vapour content in the atmosphere and more intense precipitation events. ${ }^{19}$ Increased precipitation will amplify the concentrations of waterborne pathogens in the water via sewer overflows, surface runoff of manure and other faeces, and the increased turbulence allows for re-suspension of pathogens from sediment. ${ }^{20}$

A multidisciplinary approach can be implemented to reduce cholera outbreaks and control cholera in endemic areas. This includes improving water supply and sanitation, increased cholera surveillance, practice of hand washing with soap, distribution of oral cholera vaccine, and finally, increasing cooking temperature to at least $70^{\circ} \mathrm{C}$ as the bacteria will not survive high cooking temperature.

\section{CONFLICT OF INTEREST}

None

\section{REFERENCES}

1. Elimian KO, Musah A, Mezue S, Oyebanji O, Yennan S, et al. Descriptive epidemiology of cholera outbreak in Nigeria, January-November, 2018: Implications for the global roadmap strategy. BMC Public Health 2019; 19(1):1264.

2. Ali M, Nelson AR, Lopez AL, \& Sack DA. Updated global burden of cholera in endemic countries. PLoS neglected tropical diseases 2015; 9(6):e0003832.

3. World Health Organization. Weekly epidemiological record. 89:345-356.

4. Hashizume M, Armstrong B, Hajat S, et al. The effect of rainfall on the incidence of cholera in Bangladesh. Epidemiology. 2008; 19:103110.

5. Lipp EK, Huq A, Colwell RR. Effects of global climate on infectious disease: the cholera model. ClinMicrobiol Rev. 2002; 15:757-770.

6. Zin T, Sabai AT, Saupin S, Myint T, et al. Influencing factors for cholera and diarrhoea: Water, sanitation and hygiene in impoverished rural villages of Beluran District, Sabah Malaysia. Malaysian Journal of Public Health Medicine.2015; 15:30-40

7. Xia $Y$, Fabian $P$, Stohl A, Winterhalter $M$. Forest climatology: estimation of missing values for Bavaria, Germany. 1999.

8. El-fadel M, Ghanimeh S, Maroun R, Alameddine I. 2012. Climate change and temperature rise: Implications on food and waterborne diseases.

9. Deen JL, Seidlein LV, Sur D, et al. The High Burden of Cholera in Children: Comparison of Incidence from Endemic Areas in Asia and Africa. PLoSNegl Trop Dis. 2008; 2(2):173.

10. Colwell RR, Huq A, Islam MS, et al. Reduction of cholera in Bangladeshi villages by simple filtration. Proc Natl AadSci USA. 2003; 100 (3):1051-5.

11. Shabdin ML, Othman BHR. Vertical distribution of nematodes and harpacticoid copepods in muddy and sandy bottom of intertidal zone at Kok Lawi, Sabah, Malaysia. The Raffles Bulletin of Zoology 1999; 47(2):349-363.

12. Constantin G, Colwell RR. Cholera and Climate: A Demonstrated Relationship. Trans Am ClinClimatol Assoc. 2009; 120:119-128.

13. Hunter.2003. Climate change and waterborne and vector-borne disease. Journal of Applied Microbiology.94:37S-46S.

14. Boeckmann M, Roux T, Robinson M, Areal A, Durusu D, Wernecke B., et al. Climate change and control of diarrhoeal diseases in South 
Africa: Priorities for action Connections

between temperature and diarrhoeal

disease. SAMJ: South African Medical Journal 2019; 109(6):359-361.

15. Bhandari D, Bi P, Sherchand JB, Dhimal M, \& Hanson-Easey S. Assessing the effect of climate factors on childhood diarrhoea burden in Kathmandu, Nepal. International journal of hygiene and environmental health 2020; 223 (1): 199-206.

16. Traerup SLM., Ortiz RA. \& Markandya, A. 2010. The Health Impacts of Climate Change: A Study of Cholera in Tanzania. Bc3, (January).

17. Fernandez MAL, Bauernfeind A., Jimnez JD, et al. Influence of temperature and rainfall on the evolution of cholera epidemics in Lusaka, Zambia, 2003-2006: Analysis of a time series. Transactions of the Royal Society of Tropical Medicine and Hygiene. 2009; 103(2):137-143.

18. Borneo post online. Iced beverages banned in Beluran over cholera. April 2015.

19. Trenberth K. 2011. Changes in precipitation with climate change. Clim Res.47:123-138

20. Hofstra N. Quantifying the impact of climate change on enteric waterborne pathogen concentrations in surface water. Current Opinion in Environmental Sustainability. 2011;3:471-479

21. Reyburn R., Kim DR., Emch M., Khatib A., Von SL., Ali, M. Climate variability and the outbreaks of cholera in Zanzibar, East Africa: A time series analysis. American Journal of Tropical Medicine and Hygiene. 2011; 84 (6):862-869.

22. Lopez AL, Dutta S, Qadri F, Sovann L, Pandey $\mathrm{BD}$, et al. Cholera in selected countries in Asia. Vaccine 2019. 